\title{
Study of the prophylactic activity of Terminalia chebula against induced gastric erosion in rabbit model
}

\author{
Z.A.H. Alebady \\ Veterinary Medicine College, Al-Qadissiyah University, Al-Qadissiyah, Iraq \\ Email: zanib.hatim@qu.edu.iq, Tel: 07809329479
}

(Received October 12, 2017; Accepted December 7, 2017)

\begin{abstract}
The study was designed to evaluate the prophylactic activity of Haritaki (Terminalia chebula) against induced gastric erosion in rabbit model by using $80 \%$ Ethanol for induction. The experiment continued for 16 days, during which 18 rabbits were divided into three groups (6 rabbits/ group) control group, induction group and treatment group, which received normal saline orally daily, $80 \%$ ethanol as a single dose or Terminalia chebula ethanolic extract ( $400 \mathrm{mg} / \mathrm{kg}$ ) orally daily respectively. In the last day of the experiment, a single dose of $80 \%$ ethanol was given to the animals in group 3 which received plant prophylactically, 1 hour before animals been scarified to induce gastric erosion in it. Blood samples were collected from animals in the three groups, prior to the end of the experiment, for hematological assessment of blood glucose, blood urea, blood creatinine, alanine aminotransferase test (ALT), and Gamma-Glutamyl Transferase test (GGT) and triglycerides (TG). The results showed that in the group treated with Terminalia chebula, a significant reduction in blood glucose, urea, creatinine, ALT and GGT $(65.16 \pm 0.47 \mathrm{mg} / \mathrm{dl}, 36.16 \pm 2.98 \mathrm{mg} / \mathrm{dl}, 0.72 \pm 0.00 \mathrm{mg} / \mathrm{dl}, 57.33 \pm 0.84 \mathrm{IU} / 1,19 \pm 3.82 \mathrm{IU} / \mathrm{l})$ respectively was noticed in comparison to the induction group $(174 \pm 0.36 \mathrm{mg} / \mathrm{dl}, 46 \pm 0.36 \mathrm{mg} / \mathrm{dl}, 0.83 \pm 0.003 \mathrm{mg} / \mathrm{dl}, 96 \pm 0.36 \mathrm{IU} / 1,53 \pm 0.36 \mathrm{IU} / \mathrm{l})$ and the control group $(169.5 \pm 11.60 \mathrm{mg} / \mathrm{dl}, 52.66 \pm 5.39 \mathrm{mg} / \mathrm{dl}, 0.62 \pm 0.03 \mathrm{mg} / \mathrm{dl}, 63.66 \pm 3.46 \mathrm{gm} / \mathrm{dl}, 26.33 \pm 5.90 \mathrm{mg} / \mathrm{dl})$ respectively at $(\mathrm{P}<0.05)$. TG were not significantly affected in the treatment group comparing to the induction and the control group. The data were analyzed by student's $t$-test using SPSS (Version 10). The results were expressed as mean \pm standard error (mean $\pm \mathrm{SE}$ ), $\mathrm{P}$ values $<0.05$ were considered statistically significant. The data showed a protective activity produced by T. chebula against ethanol induced gastric erosion as showed by the histopathological examination of the harvested stomach from the animals in the three groups, as the distorted superficial gland by the effect of ethanol in the mucosa were regenerated in T. chebula treated group. In conclusion, the significant improvement of the blood parameters levels in the treated animals comparing to the induction and the control group, in addition to the protective effect on tissue level suggested the possible prophylactic activity that $T$. chebula have in the studied gastric erosion condition.
\end{abstract}

Keywords: gastric erosion, Terminalia chebula, rabbits Available online at http://www.vetmedmosul.org/ijvs

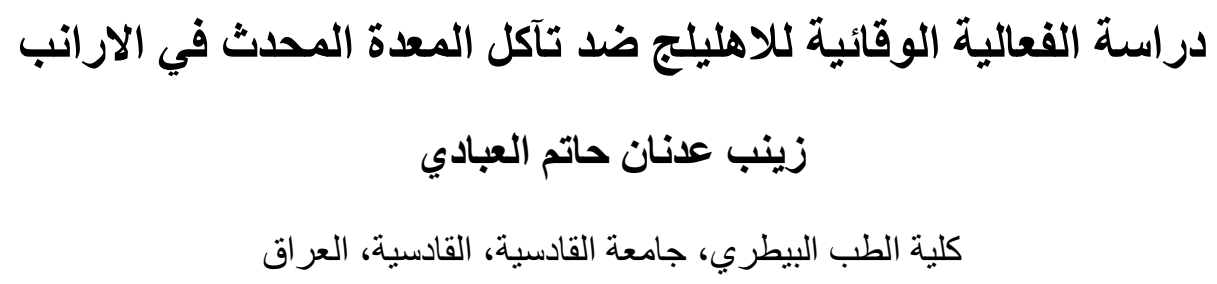

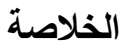

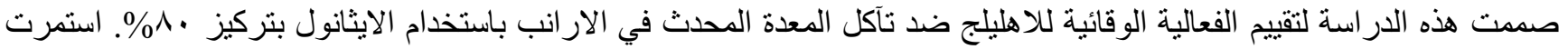

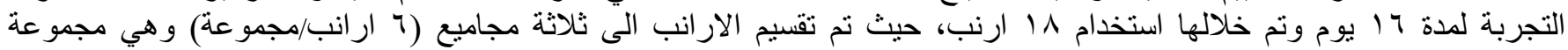

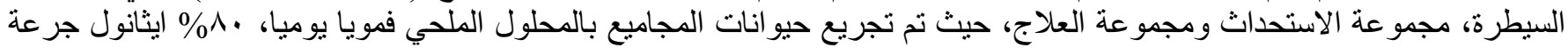

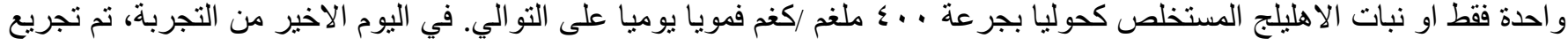




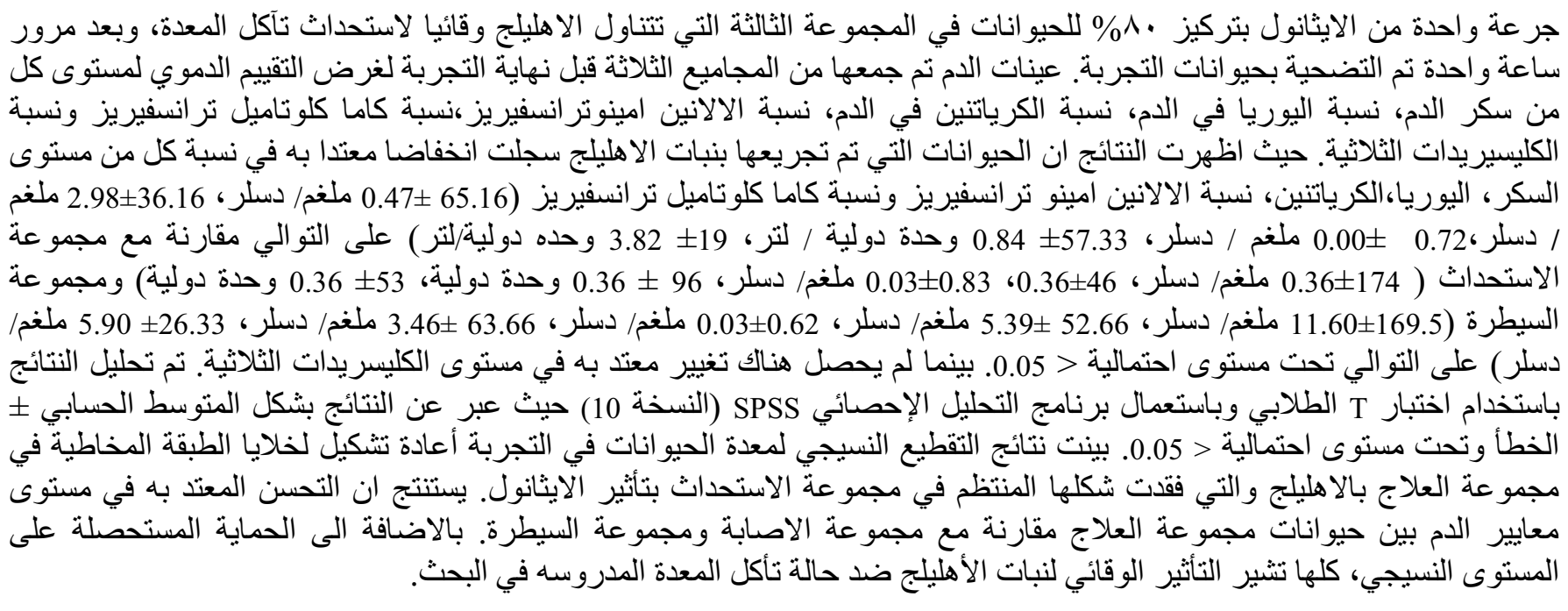

\section{Introduction}

Gastric erosions can be endoscopically described as a recognizable mucosal breaks which do not reach to the muscularis mucosae. It might last for a short-term or can also be, chronic or intermittent. Many factors can play a role in the development of gastric erosions of which Herpes simplex virus (HSV), Helicobacter pylori (H. pylori), hyperacidity, use of alcohol and nonsteroidal antiinflammatory drugs (NSAIDs), also cigarette smoking (1).

Plants have been used anciently for the treatment of various human diseases, as a potent therapeutic agents, including, cancer, ulcer, inflammations, etc. Large population in the world depend mainly on plants for medication due to the low level of side effect, and the therapeutically effective results they provide (2).

In this modern era also $75-80 \%$ of the world populations still use herbal medicine mainly in developing countries, for primary health care because of better cultural acceptability, better compatibility with the human body and less side effects. The chemical constituents present in the herbal medicine or plant are a part of the physiological functions of living flora and hence they are believed to have better compatibility with human body (3).

Terminalia chebula is a medium- to large-sized tree that can be found in the tropical and subtropical Asia. It consists of 250 species (4). Antibacterial activity of Terminalia chebula extracts against several bacterial strains have been reported (5). Terminalia chebula is considered as a traditional medicine that is consistently used to treat diseases such as urinary tract infection, gastrointestinal diseases, skin diseases, fever, diarrhea, and wound infections (4). Extracts from different parts of plant can be used for this applications such as root, flower, leaves and seeds (6).
In Terminalia chebula, $33 \%$ of the total phytoconstituents are hydrolysable tannins (which may vary from 20-50\%) and are responsible for pharmacological activity.

These tannins contain phenolic carboxylic acid like gallic acid, ellagic acid, chebulic acid and gallotannins such as 1,6 di- $O$-galloyl- $\beta$-D-glucose, $3,4,6$ tri- $O$-galloyl- $\beta-\mathrm{D}$ glucose, $2,3,4,6$ tetra- $O$-galloyl- $\beta$-D-glucose, $1,2,3,4,6$ penta-Ogalloyl- $\beta$-D-glucose. Ellagitannin such as punacalagin, casurarinin, corilagin and terchebulin and others such as chebulanin, neochebulinic acid, chebulagic acid and chebulinic acid reported in literature $(7,8)$. The tannin content varies with the geological variation. Flavonol glycosides, triterpenoids, coumarin conjugated with gallic acid called chebulin, as well as phenolic compounds were also isolated (9).

The effect of concentrated ethanol in the induction of gastric lesion was described previously(10). 40\% ethanol produce both focal mucosal hyperemia and widespread exfoliation of the surface epithelium. Massive release of mucus accompanied both events (11).

The $T$. chebula extract increased mucus production in aspirin and ethanol-induced ulcer models and showed antisecretory activity in pylorus ligated model leading to a reduction in the gastric juice volume, free acidity, total acidity, and significantly increased gastric $\mathrm{pH}$ (12).

This study aimed to discover the prophylactic effect of Terminalia chebula in induced gastric erosion in rabbits and to find it is effect on different parameters including the histopathological examination of the stomach of the treated animals in the end of the experiment and some other blood sample tests. 


\section{Materials and methods}

\section{Medicinal plants}

The fruits of Terminalia chebula (Haritaki) was purchased from local market, identified by the national Iraqi institute for herbs, the fruits of the plant were subjected to aerial drying for two weeks, after drying were grinded very well until it became as a fine powder using electric grinder (Alaraby, Egypt).

\section{Animals}

Eighteen healthy, local, domestic rabbits weighing (1750-2000) gm of both sexes were used in this study. They were supplied by the local animal market at Al-Diwaniya city. Rabbits were housed two per cage, and were fed standard oxoid pellets, also given water ad libitum.

\section{Experimental design}

Eighteen rabbits were randomly divided into three groups (6 rabbits/ group). The first group ( control group) given normal saline daily for 15 days, while each animal in the second group (induction group) received one dose of 1 $\mathrm{ml} / \mathrm{kg}$ of $80 \%$ ethanol to induced gastric erosion only in day 16 of the experiment 1 hour before the animals been sacrificed. Animals of the third group (treatment group ) received $(400 \mathrm{mg} / \mathrm{kg}$ B.W./day) of ethanol extract of T.chibula orally daily for 15 days using gavages needle (13).

\section{Preparation of ethanol extract}

Ethanolic extract of T.chibula was prepared according to the method of Le Grand (14).

\section{Gastric erosion induction in rabbits}

One $\mathrm{ml}$ of $80 \%$ ethanol was used orally to induce gastric erosion (15). Animals were fasted for 24 hour following the last dose of T.chibula extract on day 15 of the experiment. For the induction and treatment group animals, $1 \mathrm{ml} / \mathrm{kg}$ of $80 \%$ ethanol was administered orally, and one hour after the ethanol administration, animals in the three groups were sacrificed under chloroform anesthesia, and the abdomen was opened.

The stomach was removed and placed on Petri dish, then injected via any of gastric orifices with $10 \mathrm{ml}$ of formalin $10 \%$ for 10 minutes to preserve the liner layer of the stomach. After that, the stomach was incised along the greater curvature and washed gently in running tap water. Finally, it was immersed in formalin $10 \%$ to be ready afterward for sectioning.

\section{Blood samples}

At the end of experiment, after induction of gastric erosion, blood samples were taken at 9 am on the last day of the experiment, at most care by heart puncture. $5 \mathrm{ml}$ of blood could be aspirated and collected in the Ethylene diamine tetra acetic acid anticoagulant coating tube (EDTA tubes), shacking gently to be used then for haematological assessment of blood glucose, blood urea, blood creatinine, ALT, GGT, and Triglycerides by using of Reflotron ${ }^{\circledR}$ Strips.

\section{Histopathological examination}

The tissue samples were fixed in $10 \%$ buffered formalin and processed with paraffin wax. For histopathological examination, $5 \mu \mathrm{m}$ sections were stained with hematoxylin and eosin. Histopathological examination was done by pathologist assistant lecturer Khalil Gizar in the Department of Pathology, Veterinary Medicine College, Al Qadissiyah University.

\section{Data analysis}

The data were analyzed by student's $t$-test using SPSS (Version 10). The results were expressed as mean \pm standard error (mean $\pm \mathrm{SE}$ ), $\mathrm{P}$ values $<0.05$ were considered statistically significant.

\section{Results and discussion}

Terminalia chebula have been claimed to be useful in various complaints. Terminalia chebula (family Combretaceae) is distributed throughout the sub-himalayala tracks and all deciduous forest of India. The plant has been studied for its antibacterial, antiviral, antifungal, antimutagenetic activity, antioxidant activity, hypolipidemic, adaptogenic and antianaphylytic activity, gastrointestinal motility improving and anti-ulcerogenic activity, radioprotective, antidiabetic, antispasmotic, wound healing, purgative, immunomodulatory and chemopreventive activity (15). Fruit of Terminalia Chebula is composed chemically of the myrobalan fruit has tannin (24-32\%), the chief constituents of this tannin is Chebulagic acid, Chebulinic acid, Corilagin and gallic acid. It has 18 amino acids, sugar, phosphoric acid, sucicinic acid and some other acids in minute quantities. The concentration of tannin decreases in fruit as it matures and the acidity increases. Resin and purgative principle of anthraquinone and sennoside nature is also present. The seed pulp has a yellow colored oil. Ethanol serves as a most common ulcerogenic agent and when given intragastrically it produces severe gastric hemorrhagic erosions (16). The genesis of ethanol-induced gastric lesions is multifactorial with the depletion of gastric wall mucus content as one of the involved factors (17). This damage induced by ethanol may be due to mucosal leukotriene release (18). Mucosal blood flow has also been attributed to be an important factor in the damage caused by alcohol and is modulated by prostaglandin (19) Submucosal venular constriction by 
ethanol and eventual injury is caused due to perturbations of superficial mucosal cells (19) notably the mucosal mast cells leading to release of vasoactive mediators including histamine, that cause damage to gastric mucosa (20). Ethanol-induced damage to the gastric mucosa is associated with a significant production of free radicals leading to an increased lipid peroxidation and damage to the cell and cell membranes. Accumulation of activated neutrophils in the gastric mucosa may be a source of free radicals (21).

One of the most sensitive and dramatic indicators of hepatocyte injury is the release of intracellular enzymes such as ALT and AST in the circulation. During hepatic damage, these transaminases present in the liver cells leak in to the serum, resulting in increased concentrations. The elevated activities of these enzymes are indicative of cellular leakage and loss of the functional integrity of the cell membranes in liver (21). The measurement of ALT is a sensitive and valuable indicator of hepatic injury since the enzyme activity is confined to the cytoplasm of liver (22).

The effect of T.chebula on the level of blood ALT enzyme and GGT was indicate a significant reduction of it is level $(57.33 \pm 0.84 \mathrm{IU} / 1,19 \pm 3.82 \mathrm{IU} / \mathrm{l})$ which was agree with the result of (20) who also found that In Terminalia chebula treated group, liver enzyme level showed a significant decrease.

T. arjuna which is a species of Terminalia genus acts as an gastroprotective agent probably due to its free radical scavenging activity and cytoprotective nature (23).

The effect of T.chebula in lowering blood glucose level in this study $(65.16 \pm 0.47 \mathrm{mg} / \mathrm{dl})$ is also agree with the result of (24) who indicated a significant antidiabetic and renoprotective effects with the chloroform extract of $T$. chebula which is probably mediated through enhanced secretion of insulin from the $\beta$-cells of Langerhans or through extra pancreatic mechanism (24). Our result of blood glucose is also agree with the result of (25) who also used the extract of T.chebula and find that it cause a decrease in blood glucose level, serum creatinine level was also reduced which was agree with our results, while he also mentioned that blood urea level was decreased by the effect of T.chebula which disagree with our results, also it had been found (15), that treatment with T.chebula lead to prevent the elevation of serum levels of creatinine, uric acid and blood urea, which is agree with our result for blood urea while disagree for the result of serum creatinine. Another group (26) used T.chebula in induced case of hyperlipidemia. They found that the rats receiving treatment with Haritaki (T.chebula) showed significant reduction in total cholesterol, triglycerides, total protein and elevation of high density lipoprotein cholesterol. Haritaki was found to possess significant hypolipidemic activity,while our results of TG level was none significant at $(\mathrm{P}<0.05)$ while, the result of our study showed that pretreatment with $T$. chebula extract showed a significant reduction in blood glucose, urea, creatinine, ALT, and GGT $(65.16 \pm 0.47 \mathrm{mg} / \mathrm{dl}, 36.16 \pm 2.98 \mathrm{mg} / \mathrm{dl}, 0.72 \pm 0.00 \mathrm{mg} / \mathrm{dl}$, $57.33 \pm 0.84 \mathrm{IU} / 1,19 \pm 3.82 \mathrm{IU} / 1)$ respectively in comparison with the induction group $(174 \pm 0.36 \mathrm{mg} / \mathrm{dl}, 0.83 \pm 0.003$ $\mathrm{mg} / \mathrm{dl}, \quad 96 \pm 0.36 \quad \mathrm{IU} / \mathrm{l}, \quad 53 \pm 0.36 \mathrm{IU} / \mathrm{l})$ respectively at $(\mathrm{P}<0.05)$, whereas TG were not significantly affected (Table 1; Fiugre 1).

The histopathological examination of the stomach sections of the animals in the three tested groups showed a normal, mucosa layer and submucosa also with collagen fibers (Figure 2), while for the induction group an erosion in the superficial part of mucosa, produced by necrosis and destruction of the superficial glandular tissue was noticed (Figure 3), in the treatment group, the distorted superficial gland in the mucosa were regenerated, while some glands still necrotic (Figure 4), which might be due to the long duration of exposure to ethanol, or probably an after induction treatment with T.chebla is required to give a boost for the stomach mucosa recovery, which might require an addition of a fourth group of animals where the animals receive an a pre and post induction treatment with $T$. chebula for a few days then sacrificed and examined.

Table 1: Effect of T. chebula fruits ethanol extract on blood glucose, blood urea, blood creatinine, ALT, GGT, and triglycerides in $80 \%$ ethanol-induced gastric ulcer model (Mean \pm SE, $n=6$ animals).

\begin{tabular}{|c|c|c|c|c|c|c|}
\hline $\begin{array}{l}\text { Parameters } \\
\text { Group }\end{array}$ & $\begin{array}{l}\text { B.Glucose } \\
\mathrm{mg} / \mathrm{dl}\end{array}$ & $\begin{array}{l}\text { Urea } \\
\mathrm{mg} / \mathrm{dl}\end{array}$ & $\begin{array}{l}\text { Creatinine } \\
\mathrm{mg} / \mathrm{dl}\end{array}$ & $\begin{array}{l}\text { ALT } \\
\text { IU/1 }\end{array}$ & $\begin{array}{l}\text { GGT } \\
\text { IU/1 }\end{array}$ & $\begin{array}{c}\mathrm{T} . \mathrm{G} \\
\mathrm{mg} / \mathrm{dl}\end{array}$ \\
\hline $\begin{array}{l}\text { Control group } \\
\text { (normal saline) }\end{array}$ & $169.5 \pm 11.60$ & $36.16 \pm 2.98$ & $0.62 \pm 0.03$ & $63.66 \pm 3.46$ & $26.33 \pm 5.90$ & $128.5 \pm 16.05$ \\
\hline $\begin{array}{l}\text { Induction group } \\
\text { (Ethanol) }\end{array}$ & ${ }^{\mathrm{a}} 174 \pm 0.36$ & ${ }^{\mathrm{a}} 46 \pm 0.36$ & ${ }^{\mathrm{a}} 0.83 \pm 0.003$ & ${ }^{\mathrm{a}} 96 \pm 0.36$ & a $53 \pm 0.36$ & $128 \pm 0.36$ \\
\hline $\begin{array}{l}\text { Treatment group } \\
\text { (T. chebula) }\end{array}$ & ${ }^{\mathrm{a}} 65.16^{*} \pm 0.47$ & ${ }^{\text {a }} 52.66 * \pm 5.39$ & ${ }^{\mathrm{a}} 0.72 *{ } 0.004$ & a $57.33 * \pm 0.84$ & ${ }^{\mathrm{a}} 19 *_{ \pm 3.82}$ & $122 \pm 23.19$ \\
\hline
\end{tabular}

*Significant lowering effect comparing to the induction group at $\mathrm{P}<0.05$,

${ }^{a}$ Significant lowering effect comparing to the control group at $\mathrm{P}<0.05$ 


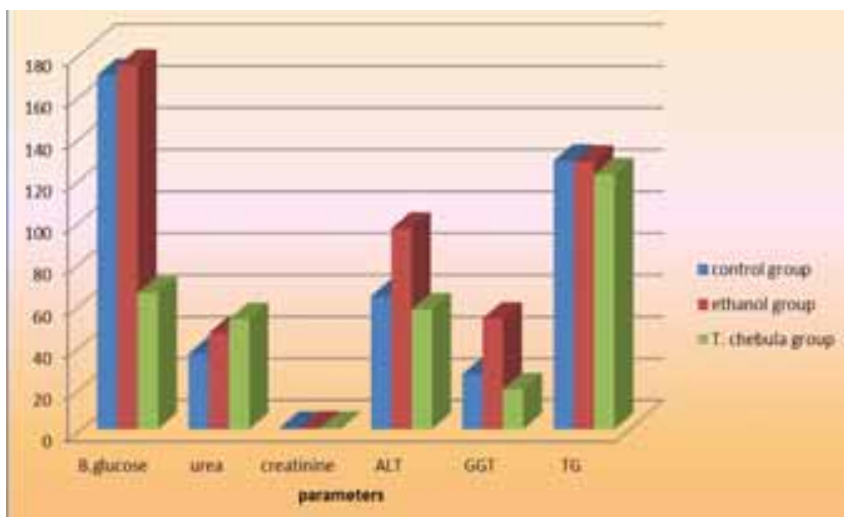

Figure 1: Effect of T. chebula fruits ethanol extract on blood glucose, blood urea, blood creatinine, ALT, GGT, and triglycerides in $80 \%$ ethanol-induced gastric ulcer model.

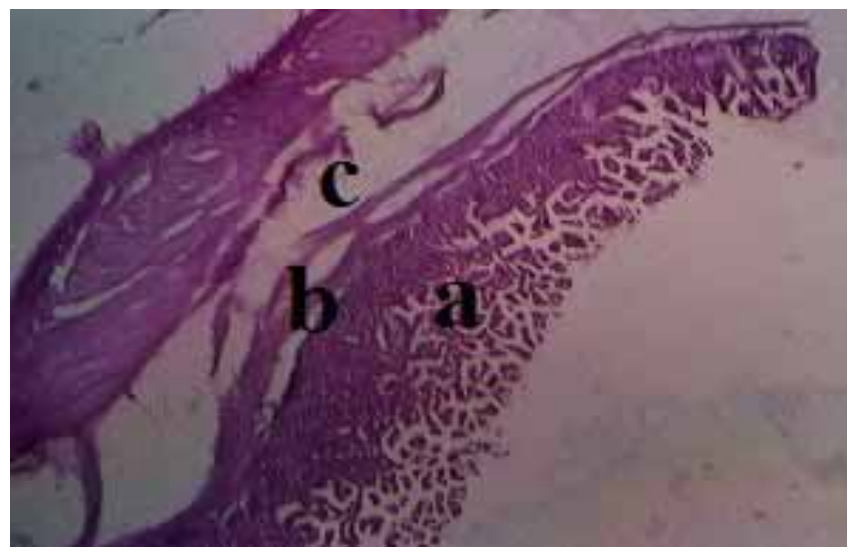

Figure 2: Control group- Normal, mucosa layer (a), submucosa with sparsely distributed collagen fibers (b) and muscularis layer (c). H\&E, 40X.

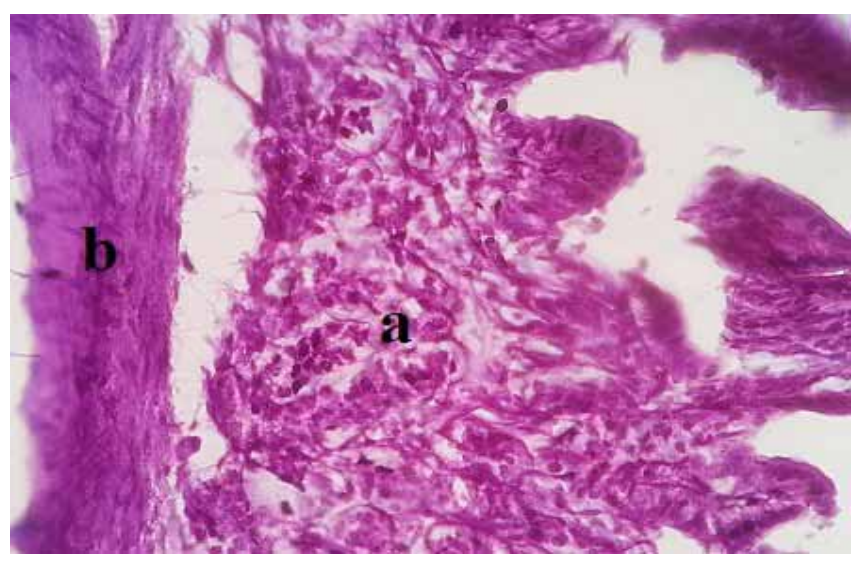

Figure 3: Control group -Normal, mucosa layer, submucosa with collagen fibers. H\&E, 400X.

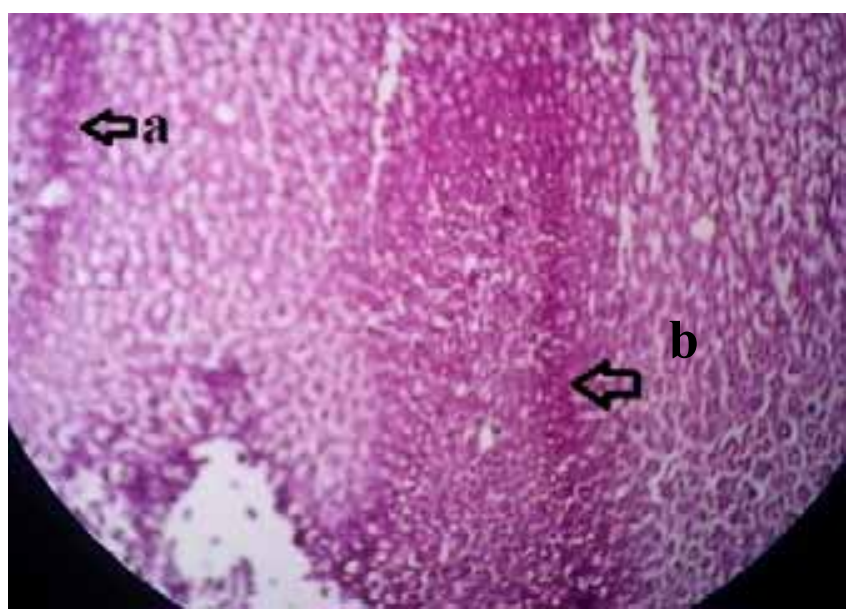

Figure 4: Induction group-There is saucer-shape erosion (a) and Wedge -shape erosion (black arrow) in the superficial part of mucosa, produced by necrosis and destruction of the superficial glandular tissue. H\&E, 100X.

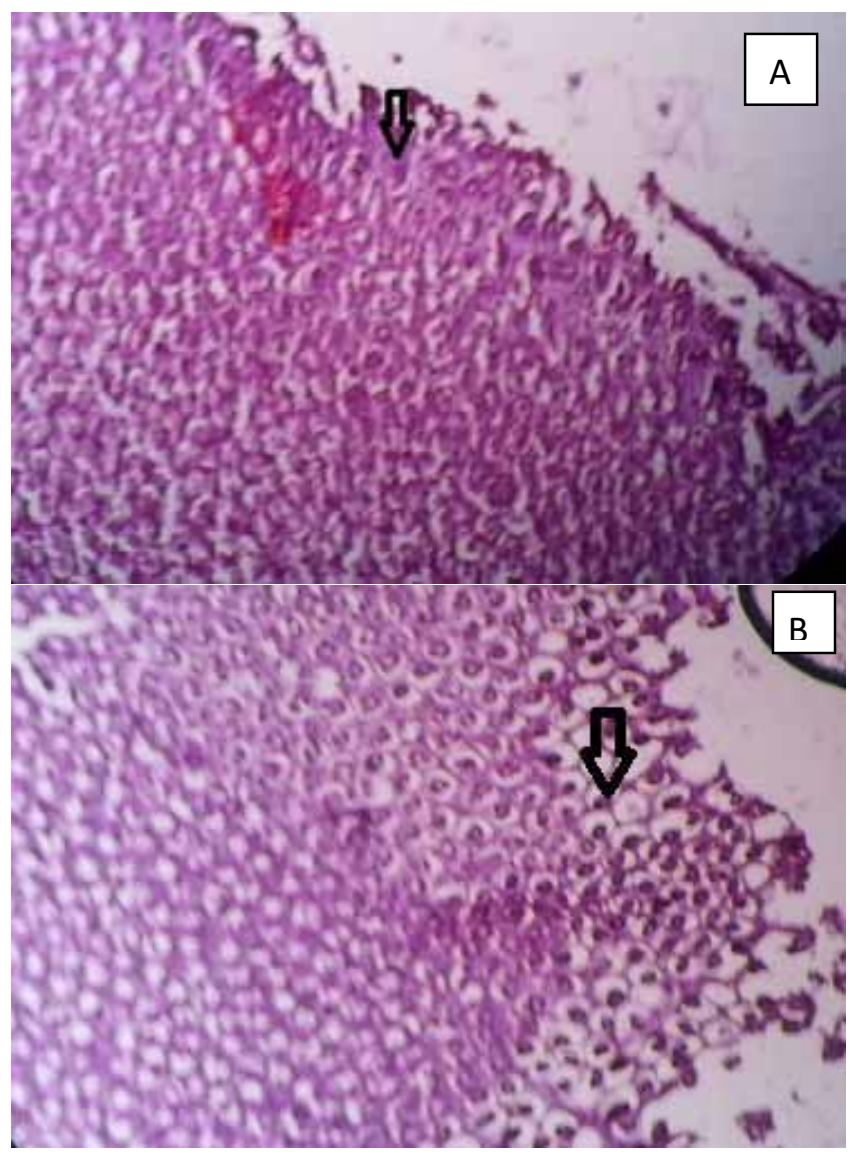

Figure 5: Induction group- $(\mathrm{A} \& \mathrm{~B})$ The superficial gland in the mucosa are distorted and necrotic (black arrow). H\&E, $100 \mathrm{X}$. 


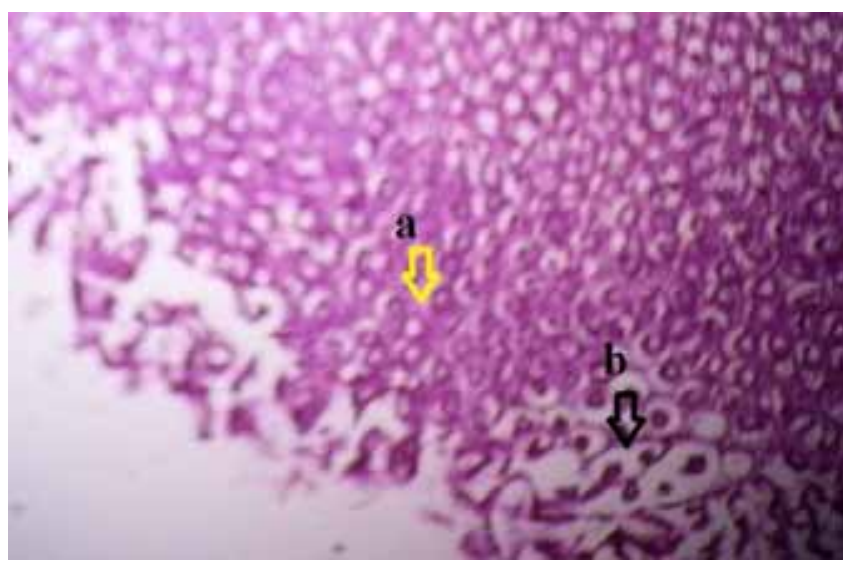

Figure 6: Treated group-Regenerated gastric erosion, (a) the distorted superficial gland in the mucosa are regenerated (yellow arrow), (b) while some glands still necrotic (black arrow). H\&E, 100X.

\section{Reference}

1. Toljamo K, Gastric erosion-clinical significance and pathology. Along term follow-up study. 2012.

2. Ajaikumar KB, Asheef M, Babu BH, Padikkala J. The inhibition of gastric mucosal injury by Punicagranatum L.(pomegranate) methanolic extract. Journal of ethnopharm. 2005;96(1):171-176.

3. Jainu M, Mohan KV, Devi CS. Gastroprotective effect of Cissus quadrangularis extract in rats with experimentally induced ulcer. Indian J Med Res. 2006;123(6):799.

4. Ammar S, Michael H, Pirkko H, Kalevi P. Inhibition of Cancer Cell Growth by Crude extract and the Phenolics of Terminalia chebula Fruit. J Ethnopharm. 2002;81:327-336.

5. Karel DK, Ammar S, Jari S, Marja K, Jyrki L, Peteri T, Kalevi P. The Structural and Conformational analyses and antioxidant activities of Chebulinic acid and its thrice-hydrolyzed derivative,2,4-chebuloyl-ßdglucopyranoside, isolated from the fruit of Terminalia chebula. ARKIVOC. 2004;7:83-105

6. Jothi D. Experimental study on antimicrobial activity of cotton fabric treated with aloe gel extract from Aloe vera plant for controlling the Staphylococcus aureus (bacterium). Afr $J$ Microbio Res. 2009;3(5):228-232.

7. Dash B. Materia Medica of Ayurveda. B. Jain Publishers, New Delhi. 1991; pp:170-174.

8. Bag A, Bhattacharyya SK, Bharati P, Pal NK, Chattopadhyay R. Evaluation of antibacterial properties of Chebulic myrobalan (fruit of Terminalia chebula Retz.) extracts against methicillin resistant Staphylococcus aureus and trimethoprim-sulphametho-xazole resistant uropathogenic Escherichia coli, Afr J Plant Sci. 2009;3(2):025-029

9. Juang LJ, Sheu SJ, Lin TC. Determination of hydrolyzable tannins in the fruit of Terminalia chebula Retz. by high-performance liquid chromatography and capillary electrophoresis. J Separa Sci. 2004;27(9):718-724

10. Han Q, Song J, Qiao C, Wong L, Xu H. Preparative isolation of hydrolysable tannins chebulagic acid and chebulinic acid from Terminalia chebula by high-speed counter-current chromatography. J SeparSci. 2006;29(11):1653-1657.

11. Chattopadhyay RR, Bhattacharyya SK. Plant Review Terminalia chebula. Pharmacognos. Rev. 2007;23:145-15.

12. Sharma P, Prakash T, Kotresha D, Ansari MA, Sahrm UR, Kumar B, Debnath J, Goli D. Antiulcerogenic activity of Terminalia chebula fruit in experimentally induced ulcer in rats. Pharm Biol. 2011;49(3):262-68.

13. Ahmadi-Naji R, Heidarian E, Ghatreh-Samani K. Evaluation of the effects of the hydroalcoholic extract of Terminalia chebula fruits on diazinon-induced liver toxicity and oxidative stress in rats. Avicenna $J$ phytomed. 2017;7(5):454.

14. Le Grand A, Wondergem PA, Verpoorte R, Pousset JL. Antiinfectious phytotherapies of the tree-savannah of Senegal (WestAfrica) II. Antimicrobial activity of 33 species. J Ethnopharma. 1988; 22(1):25-31.

15. Narayan SRS, Devi MJ, Sabitha KE, Shyamala CSD. Protective effect of a polyherbal drug, ambrex in ethanolinduced gastric mucosal lesions in experimental rats. Indian J Pharmacol. 2004;36(1):34-37.

16. Pawar AT, Gaikwad GD, Metkari KS, Tijore KA, Ghodasara JV, Kuchekar BS. Effect of Terminalia chebula fruit extract on ethylene glycol induced urolithiasis in rats. Biomed Aging pathol. 2012;2(3):99-103.

17. Shetty R, Kumar KV, Naidu MUR, Ratnakar KS. Effect of Gingko biloba extract on ethanol-induced gastric mucosal lesions in rats. Indian J Pharmacol. 2000;32:313-7.

18. Al-Harbi MM, Quershi S, Raza M, Ahmed MM, Afzal M, Shah AH. Gastric antiulcer and cytoprotective effect Commiphora molmol in rats. J Ethnopharmacol. 1997;55:141-50.

19. Vanisree AJ, Mitra K, Shyamala DCS. Antiulcerogenic ef fect of UL409 against experimentally induced gastric ulcer in rats. Indian $J$ Pharmacol. 1996;28:265-8.

20. Hollander D, Taranawski A, Gergely H, Zipser KD. Sucralfate protection of the gastric mucosa against alcohol - induced injury: A prostaglandin-mediated process. Scand J Gastroenterol. 1984;101:97102.

21. Miller TA, Henagan JM. Indomethacin decreases resistance of gastric barrier disruption by alcohol. Dig Dis Sci. 1984;29:141-9.

22. Rajesh MG, Latha MS. Protective activity of Glycyrrhiza glabra Linn. on carbon tetrachloride-induced peroxidative damage. Indian $J$ Pharmac. 2004;36:284-287.

23. Devi RS, Narayan S, Vani G, Devi CSS. Gastroprotective effect of Terminalia arjuna bark on diclofenac sodium induced gastric ulcer. Chemico-biolo interactions.2007;167(1):71-83.

24. Sivachandran S, Hariharan P. Hepatoprotective Effect of Terminalia Chebula on Gentamicin Induced Toxicity in Rats. Inter $J$ Vet Sci. 2012;1(1):31-33.

25. Nalamolu, K. R. \& Srinivas, N. Antidiabetic and renoprotective effects of the chloroform extract of Terminalia chebula Retz. seeds in streptozotocin-induced diabetic rats. BMC Comple Altern Med. 2006;6:17.

26. Senthilkumar GP, Subramanian SP. Biochemical studies on the effect of Terminalia chebula on the levels of glycoproteins in streptozotocininduced experimental diabetes in rats. J Appl Biomed. 2008; 6: 2. 